\title{
Introduction: The Young People and Agriculture ‘Problem' in Africa
}

\author{
James Sumberg, Nana Akua Anyidoho, Jennifer Leavy, \\ Dolf J.H. te Lintelo and Kate Wellard
}

\begin{abstract}
In introducing this collection of articles we argue that policy framing and policy responses to the 'problem' of young people and agriculture in Africa are hampered by a lack of research and evidence that is theoretically and historically informed, conceptually sound and context sensitive. The result is policy that is well intentioned, but unlikely to address the underlying social or agricultural concerns. To address this we outline a research agenda that places the notion of 'opportunity space' at centre stage. We suggest that an analysis of the changing structure of opportunity space for young people in agriculture and agri-food in the context of broader agrarian transitions will be particularly useful. Social difference as it affects young people's ability to exploit the agri-food opportunity space must be central to this analysis.
\end{abstract}

\begin{abstract}
1 Introduction
Despite increased public commitments to evidence-based policy in African agriculture, too often the profile of certain 'problems', and the imperative to address them quickly through policy and programmes, become separated from evidence and understanding. When this happens, policy advocates, policymakers and development planners rely heavily on 'common knowledge', anecdote and narrative to develop and argue policy alternatives. While this may be good (or at least expedient) politics, it is unlikely to result in good policy and development outcomes, particularly when the problems being addressed are associated with complex phenomena such as poverty, livelihoods, agrarian transitions, social justice or sustainability.
\end{abstract}

Unfortunately, this is the position we find ourselves in today in relation to the young people and agriculture 'problem' in Africa. We explore the nature and dimensions of this problem in greater detail in the next section of this article. The key point here is that although young people and agriculture has gained considerable prominence as a policy issue in recent years, the construction of both the problem and policy responses are hampered by:
- a lack of analysis that is theoretically and historically informed, conceptually sound and context sensitive;

- a very weak base of empirical research relating to either the nature of the problem or the potential impacts of particular policy responses (commonly, training in entrepreneurship, targeted distribution of agricultural inputs and microcredit, group farming schemes and farm mechanisation);

- a limited cadre of researchers and policy advocates who are informed about and/or actively working on the issue.

Thus, while policy advocates may be well intentioned, there can be little basis for optimism about the potential effects of policy and programmes. From a research perspective it is important to ask how common policy responses, and the framings, narratives and assumptions that underpin them, articulate with ongoing economic, social and political transitions, and with young people's own imperatives, aspirations, strategies and activities.

In 2010 the Future Agricultures Consortium (FAG) established a research theme called 'Future Farmers' that was subsequently renamed 'Young People and Agri-Food'. In March 2012 FAC and the Institute of Statistical, Social and 
Economic Research (ISSER) at the University of Ghana co-hosted an international conference on 'Young People, Farming and Food' in Accra, Ghana. This conference sought to critically examine recent empirical data relating to how young people engage with the agri-food sector in Africa (as producers, entrepreneurs, employees, consumers and citizens), and how these findings were being integrated into policy processes. It also sought to explore the dynamics of change in different components of the agri-food sector and the implications of these for young people.

In organising this conference we wanted to situate the analysis of the young people and agriculture problem in relation to the array of interacting processes, trends and forces as they affect agriculture, agri-food, agrarian economies and young people in Africa. The most important of these are:

- demographic transition and potential demographic dividend;

- urbanisation processes;

- economic growth and rising incomes and inequality;

- development of local factor markets (e.g. for land and labour);

- increasing international demand for farmland;

- increasing numbers of farmers working unviable smallholdings;

- unemployment and underemployment;

- emergence of new agricultural technology;

- rising fuel prices and the biofuels push;

- rising food prices and increased food price volatility;

- nutritional transition;

- plans for investment in infrastructure;

- widening availability of Information and Communication Technologies (ICTs);

- the Millennium Development Goals (MDGs) with their focus on food security and children's education;

- changing aspirations and expectations of both rural young people and their parents.

While these manifest themselves differently in particular contexts and settings, they are the backdrop against which both analysis of the young people and agriculture problem, and policy options, must be developed and evaluated.

The articles in this IDS Bulletin were selected from among those prepared for the conference. They draw our attention to social and economic structures, aspirations, livelihoods, land and policy, and in so doing illustrate the multiple dimensions, scales and complex dynamics of the problem (and why simplistic 'solutions' are likely to fail).

In this introductory article we set the stage by looking first at how the problem of young people and agriculture is generally specified. We then return to our claim that policy in this area is hindered by a lack of relevant research, and link this evidence gap to the contradictory nature of the narratives used to support youth policy and sectoral policy relating to young people in Africa. Finally, we outline a research agenda that we suggest has the potential to reframe the young people and agriculture problem and inform policy which is better grounded in the realities of the contemporary agrarian, social and economic transitions within which young people throughout Africa seek to establish their independent lives, either with or without agriculture.

\section{The problem of young people and agriculture}

Whether made by African governments, international agencies or local non-governmental organisations (NGOs), arguments that policy should pay more attention to the relationship between young people and agriculture generally begin with one of a small handful of observations. These include:

ongoing rural poverty;

- migration of rural young people to urban areas;

- unacceptably high levels of unemployment and underemployment among rural and urban young people;

- ageing farm populations;

- low agricultural productivity.

Essentially then the problem of young people and agriculture is framed from a perspective of either 'youth in peril' or 'agriculture in peril'. Depending on their starting point, most policy advocates highlight the growth and employment potential of a modernised, business-like agriculture to paint a picture of either 'agriculture as the saviour of young people' or 'young people as the saviour of agriculture'.

There are some important similarities between how the young people and agriculture problem is framed and the early 'push-pull' models of migration. On the one hand, a number of factors 
are commonly referred to as, in effect, 'pulling' young people away from rural areas and agriculture. These include the availability of educational opportunities and other services, and the allure of better paying and higher status jobs, most often in urban areas. More prominent in the literature is the line that young people are being 'pushed' out of agriculture against their will. Here the emphasis is on aspects of agrarian structures, economies and transitions that block young people's access to productive resources (White, this IDS Bulletin). At the forefront of these is increasing population density and the resulting pressure on land, to the point where increasing numbers of smallholder farmers in Africa are working plots that are so small as to be unviable (Jayne et al. 2012). Associated with this is the process of commodification that, in the case of Ghana, is increasingly blocking young people's access to 'family land' (Amanor 2010). Peters and Richards (2011) argue that in the case of Sierra Leone grievances around deeply rooted agrarian structures and relations that restricted young people's access to land and labour - and thus limited their ability to build a livelihood in rural areas - were fundamental to the dynamics of the 1991-2002 war. In some situations the frenzied investment in African land - for both agriculture and mining - can be expected to aggravate these historical tensions and trends (De Schutter 2011; Deininger 2011). Chinsinga and Chasukwa (this IDS Bulletin) highlight the feelings of 'powerlessness, alienation and hopelessness' expressed by young people in Malawi marginalised through 'land grabs'. The limited profitability of some kinds of agriculture, linked to the quality of natural resources, poorly developed markets or lack of investment in technology and infrastructure (e.g. irrigation), could also be seen as a push factor in some situations.

As in migration studies, there are important limitations to this kind of push-pull analysis. Is the absence of educational, health and other services in rural areas pushing young people; or is the better provision of these services in urban areas pulling them? In any case this framework does not give sufficient attention to, for example, the effects of increasing access to education, the media and communications technology on young people's aspirations and expectations (Leavy and Smith 2010) and their perceptions of rural life (Tadele and Ayalew Gella, this IDS Bulletin).
Neither does it privilege the role of young people's agency: whether pushed or pulled, the implication is that young people are being forced to act against their will. The other potentially relevant insight from migration studies, which we will return to later, is that decisions about employment and place of residence are seldom 'once and for all', which highlights the importance of a life course approach to understanding peoples' evolving engagement with agriculture. Thus, while Andrew Dorward (2009) modelled smallholder agricultural development in Africa in terms of three strategies - 'Hanging In', 'Stepping Up' and 'Stepping Out' - the life course approach reminds us that the implications of these strategies for future engagement with agriculture or agri-food more broadly may not be as permanent as first appears.

\section{A lack of research and evidence}

We posited a disjuncture between the level of interest in the young people and agriculture problem and the weak research base relating to both the nature of the problem and the potential impacts of particular policy responses. This is nothing new, as a lack of evidence relating to young people and development more generally was highlighted in the World Development Report 2007: Development and the Next Generation (World Bank 2006):

One of the biggest challenges in writing this Report was that the evidence base was uneven. Data to carry out diagnostic analysis for some topics, such as youth citizenship and migration, were limited. More importantly, there were very few rigorous evaluations of youth programs and policies for any of the transitions and issues covered in the Report (p.xv).

One reason for such an uneven evidence base is conceptual. Youth studies and youth anthropologies note that the construct of youth or young people, while intuitively appealing and having universal purchase, is not unproblematic. Youth can be understood as a group of people and as the period in between childhood and adulthood; both are imbued with distinct cultural meanings across societies, and the direction of public policy and the production of knowledge accordingly takes diverse directions (Anyidoho et al., te Lintelo, White, all in this IDS Bulletin). 
Table 1 Published papers linking young people (or youth) to Africa

\begin{tabular}{lll}
\hline & Number of hits \\
\hline Period & Total & With agric rider \\
\hline $2000-12$ & 1,684 & 63 \\
$1990-9$ & 167 & 9 \\
$1980-9$ & 32 & 0 \\
$1970-9$ & 20 & 1 \\
$1960-9$ & 5 & 0 \\
\hline
\end{tabular}

Source ISI Web of Science.

On one level the thinness of the evidence base is easy enough to illustrate. A search made of published journal articles using the ISI Web of Science yielded the results shown in Table 1, where 'total' is the number of articles that appear to link young people (or youth) and Africa, and 'with agric rider' is the subset of the total that appears to refer directly to farming or agriculture. ${ }^{1}$ Of the 1,908 total hits since 1960, only 74 (4 per cent) met the search criteria linking young people, Africa and agriculture, with the vast majority of these appearing since the year 2000. This exercise was meant to be illustrative rather than comprehensive, but two important points emerge. First, while since the late 1990s there has been an explosion in research output relating to young people in Africa, most of this literature is associated with medical and health issues, particularly HIV/AIDS (also see Kuchanny and Sumberg 2010). Second, a closer inspection of those papers that meet the search criteria linking young people and agriculture indicates that relatively few address the young people and agriculture problem in a central or significant way.

None of this is to say that there is no relevant research literature, or that particular cases or aspects of the 'problem' have not generated sustained and valuable scholarship. For example, there are growing literatures on the role of agrarian issues in motivating and sustaining young people's participation in the Sierra Leone conflict (Peters and Richards 2011; Richards 2005, 2011; Fanthorpe and Maconachie 2010) and the impacts of transportation on livelihood decisions of rural young people (Porter 2010; Porter et al. 2011; Porter et al. 2010). There is also a literature on migration behaviour of rural young people that is highly relevant (Barratt $e t$ al. 2012; van Dalen et al. 2005; Tacoli and Mabala 2010). Nevertheless, examples such as these are too few and far between to provide a broad or coherent evidence base for policymaking.

\section{Young people in policy}

The weakness of the evidence base may help to explain the diversity of policy narratives associated with young people in Africa. This diversity reflects the complexities, contradictions, struggles, fears, hopes and befuddlement that so often characterise relations between generations. Anyidoho et al. (2012) and te Lintelo (this IDS Bulletin) examine framings and narratives associated with youth policy and sectoral policies addressing young people in Africa, and note their central contradictions: while portraying young people as 'the nation's future', they simultaneously stress problems of underemployed, unemployed, vulnerability and negative behaviours such as risk taking, crime and violence.

te Lintelo suggests that national youth policies 'assert strong normative aspirations for young people, but also posit that their failure to live up to these and their inability to protect them from themselves legitimates paternalist state interventions'. Thus, while there is much rhetoric around the participation of young people in policy processes, young people are generally perceived as 'passive clients of government services' and 'constrained decision-makers' with only limited ability to shape their own destinies (te Lintelo, this IDS Bulletin). Typically, youth policies are weakly informed by evidence, and calls for participation fail to take account of need and difference. The 'youth' are presented as a homogeneous group, undifferentiated by gender, age, class or religion, and existing independently of families, communities and broader social relations (Anyidoho et al. 2012). While these views are informed in part by entrenched perspectives on the policy processes (te Lintelo, this IDS Bulletin), perhaps an even bigger challenge for policymakers is to overcome their fear of the raw political power that can be summoned by young people - as demonstrated both by their historic contributions to independence struggles and their involvement in contemporary situations of conflict and violence, from Sierra Leone to Kenya and Côte d'Ivoire. 


\section{$5 \mathrm{~A}$ research agenda}

We outline a research agenda that begins to address the imbalance between the desire to act in relation to the young people and agriculture problem and a basis on which to act. This agenda addresses four questions:

- How are opportunities for engagement with farming and agri-food more broadly structured for different young people, at different times and in different places?

- What are the implications of this structuring for consequent patterns of young people's engagement with farming and agri-food, and for livelihood, poverty, social justice and sustainability outcomes?

- How might particular policy options affect or modify these outcomes?

- What are the politics around these policy options and associated processes?

Central to this agenda is the notion of 'opportunity space'. Building on Painter et al. (1994) we use this term to describe the spatial and temporal distribution of the universe of more or less viable options that a young person may exploit as she/he attempts to establish an independent life. The opportunity space for a situated young person is a function of: global, national and regional factors including institutions, policy and demand; place; and social and cultural norms. Opportunity space might be described in terms of how dynamic, large, rich or diverse it is, reflecting in part differentiation among rural areas (e.g. in terms of access to markets and quality of natural resources) (Wiggins and Proctor 2001). An individual's ability to successfully exploit a given opportunity space is then a function of: their access to key resources; support from social relations and networks; information, knowledge and skills; attitudes (e.g. towards risk and travel); imagination, alertness and adroitness to judiciously exploit opportunities.

An exploration of the opportunity space for young people in agri-food first demands a framing of agriculture that moves beyond the current policy focus on primary production (farming) to the broader spectrum of activities that comprise the agri-food sector, including producing, retailing, exporting and marketing. In all these areas, we can look at the range of roles that young people can and do take up as producers, employers, employees and consumers.
Importantly, the concept of opportunity space also addresses the instrumentalising of young people's lives in policy. When policy in Africa addresses issues relating to youth or young people it often starts by referring to the fact that 'young people are the future of the nation'. While innocuous enough, this truism belies important assumptions about the relationship between the individual and the nation that must be critically examined. Specifically, it subordinates the development and fulfilment of individual young people to someone's (usually an older man's) vision of the greater good. Using the idea of opportunity space as a starting point allows us to see the potential of the agri-food sector for addressing young people's interests.

To understand how the agri-food opportunity space is structured and restructured, we need to examine the role of the global trends, developments, relations, policies and institutions referred to in the introductory section. How have global population growth, the World Trade Organization (WTO), rising demand for food, global consolidation in food retail, the demand for biofuels, food price spikes and the new international demand for agricultural land enlarged, diminished or otherwise restructured opportunity space, where and for whom? In addition, agrarian relations structure the agrifood opportunity space, and as these evolve - in response to the global factors identified above and their local manifestations - the nature of opportunity space changes.

Langevang and Gough (2012) provide a fascinating example of the dynamics of changing opportunity space in their study of hairdressing and dressmaking, two long-established and skilled career choices for young rural women in Ghana. While new technology (chemical hair relaxing perms) has increased demand for hairdressing services, a shift towards 'Western style' clothing and the availability of inexpensive (both new and second-hand) ready-made clothes has greatly reduced opportunities for would-be dressmakers.

If opportunity space is structured and restructured by forces acting at scales from the global to the local, young people's ability to exploit opportunity space is also influenced by a range of diverse factors. Specifically, the differential ability of young people to take advantage of agri-food opportunity space is a 
function of social factors and relations, including gender, age and class, and cultural capital. This can be seen in the varying aspirations, attitudes and engagements of young people in relation to cocoa farming activities described in the case study by Anyidoho et al. (this IDS Bulletin). In many situations these factors will determine access to key resources such as land and labour, etc. It is also important to consider that formal education and exposure to the media impact directly on young people's knowledge, skills and aspirations, and thus their interest in and willingness to engage with what might otherwise be viable agri-food livelihood opportunities.

Analysis along these lines would help shed light on the questions:

- In what situations and for what social groups is agri-food opportunity space closing down or opening up, and why?

- What factors, processes and politics are associated with different patterns of engagement with and/or resistance to these changes in agri-food opportunity space?

Seen from another perspective, the young people and agriculture problem - and restructuring of the agri-food opportunity space - addresses the processes through which food systems are 'transferred' from one generation to another.' We might think of these processes as including the transfer of: values, aspirations and narratives (e.g. about farming, food and rural life); physical resources (e.g. land); patterns, systems and styles of production, processing, marketing, etc.; technology and technology trajectories; institutions; skills and knowledge; and dietary preferences and traditions.

This transfer takes place at multiple interacting levels, and there are at least three aspects to the dynamics of transfer that deserve critical attention. The first is continuity: the transfer takes place on a continuous basis - one meal, crop operation and harvest after another. The second - incremental innovation and adaptation - sits within this continuity, and brings transformation and transfer into a single realm. The third is discontinuity, as the process of transfer is also punctuated by periods of noncontinuous (radical, disruptive) change and innovation - the emergence of new markets, new technology, new institutions, etc. There are arguments that with new commitments on the part of African governments, unprecedented levels of foreign direct investment and the promise of new technology, African agriculture is currently in (or headed towards) a period of rapid and discontinuous change.

Three research approaches would appear to be of particular interest. First, a political economy approach should help illuminate the relationships between change in the international and national arenas and change in local agrarian structures and relations. While there is a long tradition of scholarship along these lines, with only a few notable exceptions relatively little of this work has had a specific focus on young people. The critical question is how the political economy of agrarian change is changing the agri-food opportunity space available to different groups of young people in different places (e.g. Ariyo and Mortimore, this IDS Bulletin).

To build a better understanding of the determinants of different young people's interest in and success at exploiting the agri-food opportunity space, an ethnographic or sociological approach is required. Here, a central proposition is that types and levels of engagement with agrifood, and the ability to exploit agri-food opportunity space, change over the life course. For example, most rural young people need to accumulate some capital in order to launch their independent lives. Certain kinds of agriculture production of high value vegetables for example can play a critical role in this capital accumulation process, enabling them to build a house, start a trading enterprise or get married. During this period the ability to generate 'quick money' may be of much greater importance than getting established in an agricultural 'career' or than any consideration of the long-term sustainability of the production system. We might think of these short-term, 'quick money' farming activities as 'instrumental agriculture' (Okali and Sumberg, Anyidoho et al., both in this IDS Bulletin). It would be a mistake to read too much in terms of longterm intentions or livelihood contribution onto such instrumental agricultural activities.

The responsibilities that come with marriage and parenting - often including the production of food crops - may limit engagement in some of these intensive, risky, but potentially high return farming activities. Thus the relative importance 
of different crops or agri-food trading activities shifts over the life course as adult responsibilities constrain the ability to exploit some parts of the agri-food opportunity space (while perhaps opening others).

As indicated above, a focus on individual and household life courses should not lead us to conceive of young people as isolated, independent agents. Rather, it is in understanding how their life courses and the life courses of others are woven together - through a variety of social institutions and relations - that insights into engagement and disengagement, advantage and disadvantage, success and failure vis-à-vis the agri-food opportunity space will arise.

Finally, there is a clear role for a policy processes perspective in addressing the young people and agriculture problem. Here research should explore questions such as: how do actors and networks manoeuvre, and fashion particular framings and narratives to promote preferred policy options? In what ways do policymaking institutions structure access and participation in deliberation, and direct certain policy outcomes, to suggest who wins and who loses? How do policies and programmes, such as the rush towards agricultural foreign investments, hailed as solutions to problems of stagnating growth and unemployment in rural areas, play out for young people (Montilla Fernándes; Chinsinga

\section{Notes}

1 Results from 13 May 2012 topic search of ISI Web of Science databases: Social Sciences Citation Index (SSGI); Arts \& Humanities Citation Index (A\&HCI); Conference Proceedings Citation Index-Science (CPCI-S); Conference Proceedings Citation IndexSocial Science \& Humanities (CPCI-SSH). For 'Total', search string was: Topic $=($ (youth or 'young people') and (Africa or SSA or sudan or nigeria or ethiopia or kenya or ghana or senegal or mali or burkina or malawi or and Chasukwa, this IDS Bulletin)? Moreover, arguments are being made to the effect that young people should have a special call on (a right to) resources (such as land) and access to policymakers and processes. How should these arguments be assessed in relation to similar calls in the name of other groups (such as women)? What is the experience and evidence around these kinds of initiatives to date? There is of course a movement to get young people more involved in policy processes, with the assumption that such involvement will both serve an educational objective and increase the relevance and effectiveness of resulting policy (te Lintelo, this IDS Bulletin). These assumptions need to be assessed critically, with an eye to questions of representation, voice, opportunities for participation and power relations.

\section{Conclusion}

There can be little doubt that food and young people are two of the most important development concerns in Africa. It is ironic, therefore, that when these concerns are linked through the young people and agriculture problem, policymakers are forced to fall back on 'common knowledge', anecdote and narrative.

It is our sincere hope that this collection of articles will help stimulate the kind and level of research that will begin to fill what is at the moment an evidence gap of very significant proportions.

tanzania or 'south africa' or RSA or angola or mozambique or congo or togo or benin or sierra or chad or cameroon or rwanda or burundi or uganda or zaire or namibia or swaziland or lesotho or eretria or somalia or guinea or liberia or gambia). For 'With agric rider', the string 'and (agrarian or agricultur* or farm or farming or 'rural livelihood' or land or crops or livestock)' was added to the Total search string.

2 We thank Michael Mortimore for this insight. 


\section{References}

Amanor, K.S. (2010) 'Family Values, Land Sales and Agricultural Commodification in Southeastern Ghana', Africa 80.1: 104-25

Anyidoho, N.A.; Kayuni, H.; Ndungu, J.; Leavy, J.; Sall, M.; Tadele, G. and Sumberg, J. (2012) Young People and Policy Narratives in Sub-Saharan Africa, FAC Working Paper 32, Brighton: Future Agricultures Consortium

Barratt, C.; Mbonye, M. and Seeley, J. (2012) 'Between Town and Country: Shifting Identity and Migrant Youth in Uganda', Journal of Modern African Studies 50.2: 201-23

De Schutter, O. (2011) 'How Not to Think of Land-grabbing: Three Critiques of Largescale Investments in Farmland', Journal of Peasant Studies 38.2: 249-79

Deininger, K. (2011) 'Challenges Posed by the New Wave of Farmland Investment', Journal of Peasant Studies 38.2: 217-47

Dorward, A. (2009) 'Integrating Contested Aspirations, Processes and Policy: Development as Hanging In, Stepping Up and Stepping Out', Development Policy Review 27.2: 131-46

Fanthorpe, R. and Maconachie, R. (2010) 'Beyond the "Crisis of Youth"? Mining, Farming, and Civil Society in Post-war Sierra Leone', African Affairs 109.435: 251-72

ISI Web of Science, http://wokinfo.com/products tools/multidisciplinary/webofscience/ (accessed 22 August 2012)

Jayne, T.S.; Chamberlin, J. and Muyanga, M. (2012) 'Emerging Land Issues in African Agriculture: Implications for Food Security and Poverty Reduction Strategies', paper presented as part of Stanford University's Global Food Policy and Food Security Symposium Series, sponsored by the Center for Food Security and the Environment and the Freeman Spogli Institute for International Studies, Stanford, California, 12 January 2012

Kuchanny, A. and Sumberg, J. (2010) 'Survey of the Topics and Issues Addressed by Published Research Linking Young People and SubSaharan Africa, 1980-2010', draft report, Brighton: Future Agricultures Consortium

Langevang, T. and Gough, K.V. (2012) 'Diverging Pathways: Young Female Employment and Entrepreneurship in Sub-Saharan Africa', The Geographical Journal 178: 242-52

Leavy, J. and Smith, S. (2010) Future Farmers: Youth Aspirations, Expectations and Life Choices, FAC
Discussion Paper 013, Brighton: Future Agricultures Consortium

Painter, T.; Sumberg, J. and Price, T. (1994) 'Your "Terroir" and My "Action Space": Implications of Differentiation, Movement and Diversification for the "Approche Terroir" in Sahalian West Africa', Africa 64.4: 447-64

Peters, K. and Richards, P. (2011) 'Rebellion and Agrarian Transitions in Sierra Leone', Journal of Agrarian Change 11.3: 377-95

Porter, G. (2010) 'Transport Planning in SubSaharan Africa III: The Challenges of Meeting Children and Young People's Mobility and Transport Needs', Progress in Development Studies 10.2: 169-80

Porter, G.; Hampshire, K.; Mashiri, M.; Dube, S. and Maponya, G. (2010) "Youthscapes" and Escapes in Rural Africa: Education, Mobility and Livelihood Trajectories for Young People in Eastern Cape, South Africa', Journal of International Development 22.8: 1090-101

Porter, G.; Hampshire, K.; Abane, A.; Tanle, A.; Esia-Donkoh, K.; Amoako-Sakyi, R.O.; Agblorti, S. and Owusu, S.A. (2011) 'Mobility, Education and Livelihood Trajectories for Young People in Rural Ghana: A Gender Perspective', Children's Geographies 9.3-4: 395-410

Richards, P. (2011) 'A Systematic Approach to Cultural Explanations of War: Tracing Causal Processes in Two West African Insurgencies', World Development 39.2: 212-20

Richards, P. (2005) 'To Fight or to Farm? Agrarian Dimensions of the Mano River Conflicts (Liberia and Sierra Leone)', African Affairs 104.417: 571-90

Tacoli, G. and Mabala, R. (2010) 'Exploring Mobility and Migration in the Context of Rural-Urban Linkages: Why Gender and Generation Matter', Environment and Urbanization 22.2: 389-95

van Dalen, H.P.; Groenewold, G. and Schoorl, J.J. (2005) 'Out of Africa: What Drives the Pressure to Emigrate?', Journal of Population Economics 18.4: 741-78

Wiggins, S. and Proctor, S. (2001) 'How Special are Rural Areas? The Economic Implications of Location for Rural Development', Development Policy Review 19.4: 427-36

World Bank (2006) World Development Report 2007: Development and the Next Generation, Washington DC: World Bank 